\title{
An inactivated yellow fever 17DD vaccine cultivated in Vero cell cultures
}

\author{
Renata C. Pereira, Andrea N.M.R. Silva, Marta Cristina O. Souza, Marlon V. Silva, \\ Patrícia P.C.C. Neves, Andrea A.M.V. Silva, Denise D.C.S. Matos, Miguel A.O. Herrera, \\ Anna M.Y. Yamamura, Marcos S. Freire, Luciane P. Gaspar*, Elena Caride \\ Oswaldo Cruz Foundation (FIOCRUZ), Bio-Manguinhos, Avenida Brasil 4365, 21045-900, Rio de Janeiro, RJ, Brazil
}

\section{A R T I C L E I N F O}

Article history:

Available online 7 April 2015

\section{Keywords:}

Inactivated vaccine

Yellow fever

Protective response

\begin{abstract}
A B S T R A C T
Yellow fever is an acute infectious disease caused by prototype virus of the genus Flavivirus. It is endemic in Africa and South America where it represents a serious public health problem causing epidemics of hemorrhagic fever with mortality rates ranging from $20 \%$ to $50 \%$. There is no available antiviral therapy and vaccination is the primary method of disease control. Although the attenuated vaccines for yellow fever show safety and efficacy it became necessary to develop a new yellow fever vaccine due to the occurrence of rare serious adverse events, which include visceral and neurotropic diseases. The new inactivated vaccine should be safer and effective as the existing attenuated one. In the present study, the immunogenicity of an inactivated 17DD vaccine in C57BL/6 mice was evaluated. The yellow fever virus was produced by cultivation of Vero cells in bioreactors, inactivated with $\beta$-propiolactone, and adsorbed to aluminum hydroxide (alum). Mice were inoculated with inactivated 17DD vaccine containing alum adjuvant and followed by intracerebral challenge with 17DD virus. The results showed that animals receiving 3 doses of the inactivated vaccine $(2 \mu \mathrm{g} /$ dose $)$ with alum adjuvant had neutralizing antibody

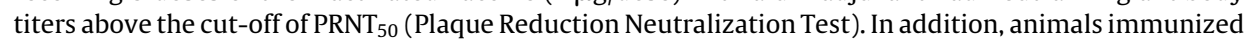
with inactivated vaccine showed survival rate of $100 \%$ after the challenge as well as animals immunized with commercial attenuated 17DD vaccine.
\end{abstract}

(C) 2015 Elsevier Ltd. All rights reserved.

\section{Introduction}

Yellow fever is a non-contagious acute infectious disease caused by the yellow fever virus, genus Flavivirus, family Flaviviridae [1,2]. It is a serious public health problem in the Americas [3] with clinical symptoms that may vary from mild to severe disease characterized by sudden onset of fever and jaundice. The most severe forms also include hepatorenal syndrome, bleeding, shock and eventually evolve to death [2,4,5]. Approximately $15 \%$ of infected people develop moderate or severe clinical disease [6]. There is no specific treatment and vaccination is the most effective method of preventing yellow fever $[7,8]$.

The attenuated vaccine was developed in 1936 by Theiler \& Smith by attenuating yellow fever virus Asibi strain through serial passages in tissue culture and animals, originating the 17D attenuated vaccine. Nowadays, there are two licensed vaccines available

\footnotetext{
* Corresponding author.

E-mail address: lgaspar@bio.fiocruz.br (L.P. Gaspar).
}

in the international market, the first vaccine uses the 17D-214 strain and the second uses the 17DD strain [9]. Bio-Manguinhos has been producing yellow fever attenuated 17DD vaccine for more than 6 decades being the world largest producer. The attenuated vaccine is administered in a single subcutaneous dose and confers immunity for at least 10 years [10].

Despite the good records of efficacy and safety, rare cases of serious adverse events (SAEs) have been reported in every yellow fever attenuated strains employed in vaccine production worldwide. The SAEs include the yellow fever vaccine-associated viscerotropic disease (YEL-AVD) and the yellow fever vaccine-associated neurotropic disease (YEL-AND). The YEL-AVD is a fulminant infection in the liver and other vital organs with $60 \%$ of case fatality rate. The YEL-AND is caused by the vaccine virus neuroinvasion and has $1-2 \%$ of case fatality rate $[8,9,11]$.

Aiming to produce a vaccine with an improved safety profile, Bio-Manguinhos is developing an inactivated vaccine for yellow fever from the 17DD virus strain. The aim of this work was to evaluate the humoral immune response of an inactivated yellow fever 17DD vaccine in C57BL/6 mice. 


\section{Materials and methods}

\section{1. $17 D D$ virus production in bioreactor}

Yellow fever 17DD virus derived from the vaccine batch 035VFA035P, Fiocruz, Brazil, was produced through cultivation in Vero (African green monkey kidney) cells in a $3 \mathrm{~L}$ bioreactor Bioflo model 110 (New Brunswick Scientific, USA) operated in batch mode using a commercial serum-free medium VP-SFM (Gibco, USA) and $3 \mathrm{~g} / \mathrm{L}$ Cytodex microcarriers (GE Healthcare, USA).

\subsection{Virus clarification and purification}

Clarification was performed by filtration through $8 \mu \mathrm{m}$, 3-0.8 $\mu \mathrm{m}$ and $0.45-0.22 \mu \mathrm{m}$ (Sartorius, USA) series of cellulose acetate membranes. Virus purification was performed by ion exchange chromatography (Äkta Purifier, Amersham Bioscience) yielding a purified batch named VINFLAP001/2010. Under operating conditions, the purifications steps are quite efficient, showing high product recovery and efficient DNA clearance as described before [12]. The level of host cell protein (HCP) was considered high indicating the need for targeting HCP in a subsequent step. Quantification of total proteins was carried out using the BCA protein assay kit (Pierce ${ }^{\circledR}$ ) according to manufacturer's instructions.

\subsection{Virus inactivation}

For viral inactivation the batch was previously filtered through a $0.22 \mu \mathrm{m}$ membrane and the $\mathrm{pH}$ was adjusted to $8.5 \mathrm{using} 1 \mathrm{~N} \mathrm{NaOH}$. The $\beta$-propiolactone inactivating agent, 1:3000 dilution (Natalex, $97 \%$ purity), was added to the suspension, followed by incubation at $4{ }^{\circ} \mathrm{C}$ under constant agitation of $100 \mathrm{rpm}$ for $24 \mathrm{~h}$. For hydrolysis of the $\beta$-propiolactone after the inactivation procedure, the suspension was maintained at $37^{\circ} \mathrm{C}$ for $2 \mathrm{~h}$. The inactivation process resulted in the batch, purified and inactivated VINFLAPI001/2010 virus sample which was used in the immunogenicity assay. Kinetics of yellow fever 17DD virus inactivation process in the range of 10 to $200 \mathrm{~mL}$ show that after $4 \mathrm{~h}$ of virus incubation with $\beta$-propiolactone no infectious particle is detected (data not shown).

\subsection{Testing of residual live virus}

Virus inactivation was confirmed through different methodologies: virus titration (plaque assay), immunofocus and passages in cell culture (cytopathic effect analysis). The sample was considered inactivated only when approved in the three trials. The same reference virus titer $8.46 \log _{10} \mathrm{PFU} / \mathrm{mL}$ was used as positive control in all inactivation tests.

\subsubsection{Virus titration}

To perform a plaque assay, ten-fold dilutions of the inactivated viral suspension were prepared, and $200 \mu \mathrm{L}$ aliquots were inoculated onto Vero susceptible cell monolayers ( 6 well plates) with a density of $1.0 \times 10^{5} \mathrm{cells} / \mathrm{cm}^{2}$, in a total of 18 replicates. After 7 days of incubation $\left(37^{\circ} \mathrm{C} / 5 \% \mathrm{CO}_{2}\right)$, the monolayer was observed for the presence or absence of lysis plaques.

\subsubsection{Immunofocus}

In order to perform the immunofocus assay, Vero cell monolayers with $1.0 \times 10^{5}$ cells $/ \mathrm{cm}^{2}$ density were prepared $24 \mathrm{~h}$ in advance in 6 well plates. Each well plate was inoculated with $200 \mu \mathrm{L}$ of viral suspension, accounting a total of 12 replicates. After 7 days of incubation $\left(37^{\circ} \mathrm{C} / 5 \% \mathrm{CO}_{2}\right.$ ) revelation was performed using a specific monoclonal antibody for yellow fever (2D12).

\subsubsection{Serial passage in cell culture}

In the cell-based assay, $5 \mathrm{~mL}$ of the inactivated viral suspension were initially inoculated into five $175 \mathrm{~cm}^{2}$ cell culture flasks containing $1.0 \times 10^{5}$ cells $/ \mathrm{cm}^{2}$ each. The flasks were incubated at $37^{\circ} \mathrm{C} / 5 \% \mathrm{CO}_{2}$ and the cell monolayer was assessed daily using an inverted microscope to verify the occurrence of cytopathic effect (CPE). Every 7 days, $5 \mathrm{~mL}$ of the viral supernatant was removed from each bottle and inoculated in new flasks. Three propagations into cell cultures were performed. Thereby, the suspension was evaluated for a total period of 21 days, the absence of CPEs during this period confirmed that the viral inactivation had been successful.

\subsection{Formulation of inactivated vaccine with alum adjuvant}

For the immunogenicity assay, the viral batch was formulated with $0.2 \%$ aluminum hydroxide (Alhydrogel; Brenntag, EUA) on the day prior to immunization. Samples containing 17DD virus in the absence of adjuvant and a vial containing only adjuvant in HEPES buffer were used as controls. Samples were left for $2 \mathrm{~h}$ in constant agitation at $4{ }^{\circ} \mathrm{C}$, after this period $500 \mu \mathrm{L}$ were collected from each vial for process control by enzyme immunoassay (ELISA). After agitation vials were kept at $4{ }^{\circ} \mathrm{C}$ until use in immunogenicity assay. Sample was immediately storage under $-70^{\circ} \mathrm{C}$ after harvest, clarification, purification by ion exchange chromatography and inactivation by $\beta$-propiolactone. Under these operating conditions, no modification on virus stability was observed.

\subsection{Animals}

C57BL/6 mice (female, 4 weeks old) were provided by the Laboratory Animals Breeding Center (CECAL-FIOCRUZ), the supply was carried out using a protocol approved by the Institutional Committee of Animal Care and Experimentation (CEUA-FIOCRUZ: LW-28/11).

\subsection{Mouse immunization studies}

For humoral immune response and challenge study, a total of one hundred forty four mice ( 9 groups, 16 animals each) were inoculated as follows; groups 1 and 2 received three doses of $100 \mu \mathrm{L}$ of HEPES buffer and alum respectively. Groups 3-8 were immunized using $100 \mu \mathrm{L}$ of purified inactivated vaccine (batch VINFLAPI001/2010) in the presence or absence of alum adjuvant at a concentration of $2 \mu \mathrm{g} /$ dose. A positive control group (group 9) was immunized with a single dose of $2.33 \log _{10}$ PFU/100 $\mu \mathrm{L}$ of the commercial live attenuated yellow fever 17DD vaccine (Bio-Manguinhos-FIOCRUZ, Brazil) at day 0. Immunizations were performed at days 0,14 and 28 by the subcutaneous route.

\subsubsection{Neutralization assay}

Serum samples were collected before the first immunization (pre-immune sera) and on 12, 26 and 40 days post infection (DPI) to analyze the humoral response. Initially, samples were treated for $30 \mathrm{~min}$ at $56^{\circ} \mathrm{C}$, subsequently antibody titers were determined by $50 \%$ PRNT50 on Vero cells, considering the cut-off of $794 \mathrm{mIU} / \mathrm{mL}$ or $2.9 \log _{10} \mathrm{mIU} / \mathrm{mL}$ as described by Simões. PRNT $_{50}$ was conducted in serial four-fold dilutions starting at 1:16 in 6 well tissue culture plates, as described elsewhere [13]. Seroconversion was considered by a four-fold increase in serum neutralizing antibody titers.

\subsection{Protection against lethal challenge}

Lethal challenge by intracerebral injection occurred at 42 DPI. Fourteen days after the last immunization with purified inactivated vaccine, one hundred eight animals ( 4 animals in each group 
Table 1

Geometric mean titers of neutralizing antibodies of the groups after immunization with batch VINFLAPI001/2010.

\begin{tabular}{|c|c|c|c|c|c|}
\hline \multirow[t]{2}{*}{ Groups } & \multicolumn{5}{|l|}{ GMT (mIU/mL) (CI95\%) } \\
\hline & Immunization & Preimmune & 12 DPI & 26 DPI & 40 DPI \\
\hline 1 & HEPES buffer ( 3 doses) & $242(169-345)$ & $101(74-138)$ & $265(218-322)$ & $159(112-225)$ \\
\hline 2 & $\mathrm{Al}(\mathrm{OH})_{3}(3$ doses $)$ & $842(574-1233)$ & $263(168-409)$ & $294(187-461)$ & $283(209-382)$ \\
\hline 3 & Inactivated 17DD (1 dose) & $592(332-1054)$ & $209(129-338)$ & $548(331-905)$ & $348(207-586)$ \\
\hline 4 & Inactivated 17DD $+\mathrm{Al}(\mathrm{OH})_{3}(1$ dose $)$ & $443(314-622)$ & $213(125-363)$ & $614(466-809)$ & $278(177-436)$ \\
\hline 5 & Inactivated 17DD (2 doses) & $270(183-397)$ & $130(87-194)$ & $367(251-537)$ & $293(211-407)$ \\
\hline 6 & Inactivated $17 \mathrm{DD}+\mathrm{Al}(\mathrm{OH})_{3}(2$ doses $)$ & $371(285-483)$ & $160(105-244)$ & $517(368-722)$ & $338(229-498)$ \\
\hline 7 & Inactivated 17DD ( 3 doses) & $613(398-944)$ & $189(115-310)$ & $386(309-480)$ & $433(308-608)$ \\
\hline 8 & Inactivated $17 \mathrm{DD}+\mathrm{Al}(\mathrm{OH})_{3}$ (3 doses) & $292(179-477)$ & $204(128-324)$ & $805(579-1116)$ & $922(666-1276)$ \\
\hline 9 & Attenuated vaccine ( 1 dose) & $180(125-257)$ & $3794(2046-5420)$ & $2082(1479-2924)$ & $2259(1531-3326)$ \\
\hline
\end{tabular}

were submitted to analysis of cellular response by ELISPOT, leaving 12 mice for lethal challenge) were challenged by intracerebral injection of $100 \mathrm{LD}_{50}$ of $17 \mathrm{DD}$ virus ( $13 \mathrm{Z}$ secondary seed lot). Subsequently, the animals were monitored for 21 days for observation of symptoms such as weight loss, prostration, paralysis or death. After this period, the surviving animals were euthanized by an overdose of sodium thiopental.

\subsection{Isotyping of immunoglobulins}

To determine the isotype profiles of immunoglobulins involved in the humoral response, subtyping was performed by ELISA for IgG1 and IgG2a antibodies in the sera collected 40 days after first immunization.

Briefly, the microplates (Maxisorb; Nunc, USA) were coated with $10 \mu \mathrm{g} / \mathrm{mL}$ of whole virus particle obtained in cell culture (yellow fever 17DD vaccine, first passage in Vero cells) diluted in $100 \mu \mathrm{L}$ of carbonate buffer $0.05 \mathrm{M} \mathrm{pH} 9.6$ and incubated overnight at $4{ }^{\circ} \mathrm{C}$. The day after, plates were washed three times with phosphatebuffered saline containing $0.05 \%(\mathrm{v} / \mathrm{v}$ ) of Tween-20 (wash solution) and blocked at $37^{\circ} \mathrm{C}$ for $2 \mathrm{~h}$ with blocking solution of PBS containing $5 \%(\mathrm{w} / \mathrm{v})$ non-fat milk with $1 \%(\mathrm{w} / \mathrm{v})$ of bovine serum albumin (BSA, Sigma Co.). The serum samples were diluted 1/50 in blocking solution, distributed in duplicates for each isotype and incubated at room temperature for $1 \mathrm{~h}$. After incubation, half part of each plate received antimouse-IgG1 conjugated to HRP or anti IgG2a conjugated to HRP (Southern Biotech, Birmingham$\mathrm{AL}$ ), so that each serum sample was measured for a given isotype at the same time and same plate, followed by incubation for $1 \mathrm{~h}$ at room temperature. Unlabeled antibodies were removed by washing five times and the reaction was accomplished with tetramethylbenzidine substrate (Sigma, USA). After $15 \mathrm{~min}$, the reaction was stopped by addition of $2 \mathrm{M} \mathrm{H}_{2} \mathrm{SO}_{4}$ solution and the plates were read at $450 \mathrm{~nm}$ on VERSAmax ELISA reader (Molecular Devices). The results were expressed in optical densities. The absorbance for immunized mice were found to be consistently lower than 0.100 and results were considered positive when above 0.300 .

\subsection{Statistical analyzes}

Statistical analysis was performed using SPSS software (Statistical Package for Social Sciences), version 17.0. The assessment of normality was done previously in all groups by the frequency histogram and the Shapiro-Wilk test. Groups with normal distribution were compared by One Way ANOVA and Tukey tests. The non-normal groups were analyzed by Mann-Whitney or Kruskal-Wallis tests. In all cases, differences were considered significant when $P$ values were less than or equal to 0.05 $(P \leq 0.05)$.

\section{Results}

\subsection{Immunogenicity of the purified inactivated vaccine in mice}

A total of $4.400 \mathrm{~mL}$ of 17DD virus with a titer of $8.08 \log _{10} \mathrm{PFU} / \mathrm{mL}$ was produced in bioreactors using Vero cells in presence of microcarriers, using serum-free medium. This virus generated the batch VINFLAPI001/2010 that after addition of alum adjuvant was used in the immunogenicity assay.

Sera collected from animals were analyzed by PRNT $_{50}$ and geometric mean titers of neutralizing antibodies are presented in Table 1 . The results showed that with $12 \mathrm{DPI}$, the animals had not developed neutralizing antibodies above the cut-off, except for group 9, which was immunized with one dose of the commercial attenuated yellow fever vaccine that has elicited broadly neutralizing antibodies titers $(3794 \mathrm{mIU} / \mathrm{mL})$. At $26 \mathrm{DPI}$, only groups 8 and 9 showed to have high antibody titers. The group immunized under three doses of the vaccine with alum (group 8) showed significant increase in Geometric Mean Titer (GMT) $(805 \mathrm{mIU} / \mathrm{mL})$, with statistically significant difference compared to the group 7 $(P<0.05$; Mann-Whitney), that was immunized with the vaccine without adjuvant and not achieved the cut-off value $(386 \mathrm{mIU} / \mathrm{mL})$. However, this value is significantly lower than group $9(P<0.05$; Mann-Whitney), which was immunized with attenuated vaccine $(2082 \mathrm{mIU} / \mathrm{mL})$. At $40 \mathrm{DPI}$, the response profile was similar to day 26 when only groups 8 and 9 were above the cut-off. Group 8 $(922 \mathrm{mIU} / \mathrm{mL})$ was still significantly different $(P<0.05$ seroconversion Mann-Whitney) from group $7(433 \mathrm{mIU} / \mathrm{mL})$ and group 9 (2259 mIU/mL).

The analysis of GMTs over time showed a significant increase in neutralizing antibody titers in group $8(P<0.05$; Kruskal-Wallis $)$ and although there was a decline in the titers of group 9 with $26 \mathrm{DPI}$ and $40 \mathrm{DPI}$, this decrease was not statistically significant $(P>0.05$; Kruskal-Wallis). Boxplot is a data visualization in Log, which allows to observe the dispersion of the titers obtained in each group (Fig. 1).

The overall seroconversion rate (Table 2) was also consistently greater in the adjuvant group with three doses of the inactivated vaccine (group 8 ) when compared with the non-adjuvant group 7 , where $43.75 \%$ (7/16) and 6.25\% (1/16) individuals seroconverted, respectively. As expected, the group immunized with the live attenuated vaccine (group 9) showed 100\% of seroconversion twelve days after inoculation.

\subsubsection{Protection against lethal challenge}

Fourteen days after the last immunization (42 DPI), animals were challenged by intracerebral route with $100 \mathrm{LD}_{50}$ of $17 \mathrm{DD}$ virus. Rates of protection (Table 3 ) showed that groups receiving a single dose of inactivated vaccine with and without adjuvant presented $0 \%$ survival. The analysis among groups receiving two 

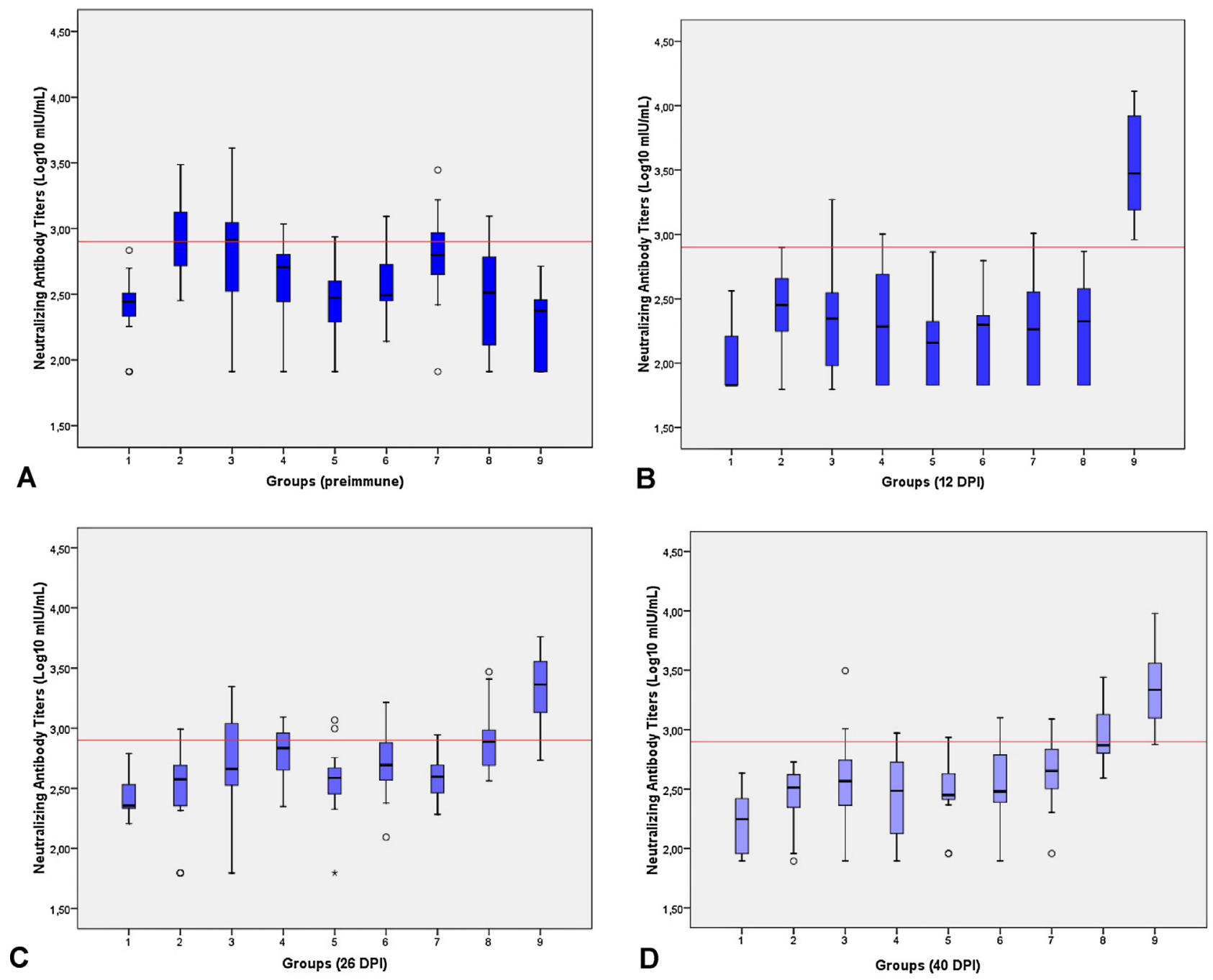

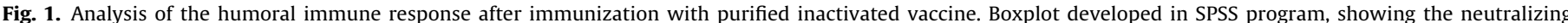

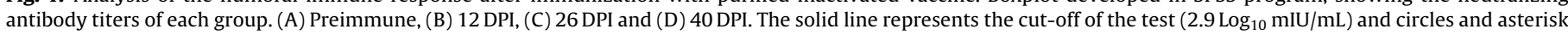
the outliers.

and three doses of inactivated vaccine with and without adjuvant (groups 5-8), highlighted the importance of the adjuvant in protecting response. Survival rate was higher in animals belonging to groups that received inactivated vaccine in the presence of alum adjuvant. It was also observed that animals immunized with two doses of vaccine formulated with adjuvant showed higher survival rates than those immunized with three doses of inactivated vaccine, but without adjuvant. The group immunized with one dose of attenuated vaccine, as well as the group that received three doses of inactivated vaccine containing adjuvant showed a survival rate of $100 \%$.

\subsubsection{Evaluation of the immunoglobulin isotype profile}

To determine the immunoglobulin isotype involved in humoral responses, sera collected 40 days after immunization with the purified inactivated vaccine was subjected to ELISA for IgG1 and IgG2a subtyping. Sera from animals immunized with inactivated vaccine (groups 3 to 8 ), as well as the groups vaccinated with the

Table 2

Analysis of sera by $\mathrm{PRNT}_{50}$, which defined the seroconversion ${ }^{\mathrm{a}}$ rate of the groups immunized with the purified inactivated vaccine.

\begin{tabular}{|c|c|c|c|c|}
\hline \multirow[t]{2}{*}{ Groups } & \multicolumn{4}{|c|}{ \% Seroconversion PRNT $_{50}$ (no of animals seroconverted/total) } \\
\hline & Immunization & $12 \mathrm{DPI}$ & $26 \mathrm{DPI}$ & $40 \mathrm{DPI}$ \\
\hline 1 & HEPES buffer ( 3 doses) & $0 \%(0 / 16)$ & $0 \%(0 / 16)$ & $0 \%(0 / 16)$ \\
\hline 2 & $\mathrm{Al}(\mathrm{OH})_{3}$ (3 doses) & $0 \%(0 / 16)$ & $0 \%(0 / 16)$ & $0 \%(0 / 16)$ \\
\hline 3 & Inactivated 17DD ( 1 dose) & $6.70 \%(1 / 15)$ & $20 \%(3 / 15)$ & $6.70 \%(1 / 15)$ \\
\hline 4 & Inactivated 17DD $+\mathrm{Al}(\mathrm{OH})_{3}(1$ dose $)$ & $0 \%(0 / 16)$ & $6.25 \%(1 / 16)$ & $0 \%(0 / 16)$ \\
\hline 5 & Inactivated 17DD ( 2 doses) & $6.70 \%(1 / 15)$ & $20 \%(3 / 15)$ & $13.33 \%(2 / 15)$ \\
\hline 6 & Inactivated 17DD $+\mathrm{Al}(\mathrm{OH})_{3}$ (2 doses) & $0 \%(0 / 16)$ & $0 \%(0 / 16)$ & $6.25 \%(1 / 16)$ \\
\hline 7 & Inactivated 17DD ( 3 doses) & $0 \%(0 / 16)$ & $6.25 \%(1 / 16)$ & $6.25 \%(1 / 16)$ \\
\hline 8 & Inactivated 17DD $+\mathrm{Al}(\mathrm{OH})_{3}$ (3 doses) & $6.25 \%(1 / 16)$ & $43.75 \%(7 / 16)$ & $43.75 \%(7 / 16)$ \\
\hline 9 & Attenuated vaccine ( 1 dose) & $100 \%(16 / 16)$ & $87.50 \%(14 / 16)$ & $93.75 \%(15 / 16)$ \\
\hline
\end{tabular}

a Seroconversion is a four-fold increase or more in neutralizing antibody titers compared to pre-immune sera. 
Table 3

Survival rate of C57BL/6 mice immunized with purified inactivated vaccine and challenged on day 42 with 17DD virus.

\begin{tabular}{|c|c|c|c|c|}
\hline Groups & No of animals & No of doses & Inoculum & Percentage of survival (live/total) \\
\hline 1 & $11^{\mathrm{a}}$ & 3 & HEPES buffer & $18.1 \%(2 / 11)$ \\
\hline 2 & 12 & 3 & $\mathrm{Al}(\mathrm{OH})_{3}$ & $16.7 \%(2 / 12)$ \\
\hline 3 & 12 & 1 & Inactivated 17DD & $0 \%(0 / 12)$ \\
\hline 4 & 12 & 1 & Inactivated $17 \mathrm{DD}+\mathrm{Al}(\mathrm{OH})_{3}$ & $0 \%(0 / 12)$ \\
\hline 5 & 12 & 2 & Inactivated 17DD & $8.3 \%(1 / 12)$ \\
\hline 6 & 12 & 2 & Inactivated $17 \mathrm{DD}+\mathrm{Al}(\mathrm{OH})_{3}$ & $41.7 \%(5 / 12)$ \\
\hline 7 & 12 & 3 & Inactivated 17DD & $16.7 \%(2 / 12)$ \\
\hline 8 & 12 & 3 & Inactivated $17 \mathrm{DD}+\mathrm{Al}(\mathrm{OH})_{3}$ & $100 \%(12 / 12)$ \\
\hline 9 & 12 & 1 & Attenuated vaccine & $100 \%(12 / 12)$ \\
\hline
\end{tabular}

a One animal died after intracerebral inoculation.

commercial attenuated vaccine (group 9) had optical density less than 0.3 when performed the assay for IgG2a isotype. All groups were negative for this isotype (Fig. 2A). However, all animals were positive for IgG1 isotype (Fig. 2B), with the exception of those immunized with attenuated vaccine which were negative for both immunoglobulin isotypes. The groups immunized with three doses of inactivated vaccine (groups 7 and 8) presented the highest concentrations of immunoglobulin IgG1 isotype.

\section{Discussion}

Yellow fever is a serious public health problem in Africa and South America [3,14]. Bio-Manguinhos is the world largest producer of attenuated yellow fever vaccine in embryonated eggs which has good efficacy and safety profiles. However, the development of a new vaccine would be of extreme importance to reduce or eliminate serious adverse events reported after vaccination with virus 17D-based vaccines produced worldwide. Moreover, an inactivated vaccine could potentially be used in elderly people and in those with contraindications to the attenuated 17DD vaccine including infants $<9$ months of age, immunosuppressed individuals, pregnant and nursing women, people with a background of thymectomy and people allergic to egg proteins and gelatin [9] and [8].

The success of inactivated licensed vaccines for other flaviviruses such as vaccines for tick-borne encephalitis and Japanese encephalitis suggests that an effective vaccine also can be developed for yellow fever [15].

Inactivated vaccines are often preferred for safety reasons. Two main points should be addressed in the development of these vaccines: (i) it is necessary to inactivate completely infectious virus to ensure the safety of the vaccine and (ii) essential viral epitopes are

\section{A}

IgG1

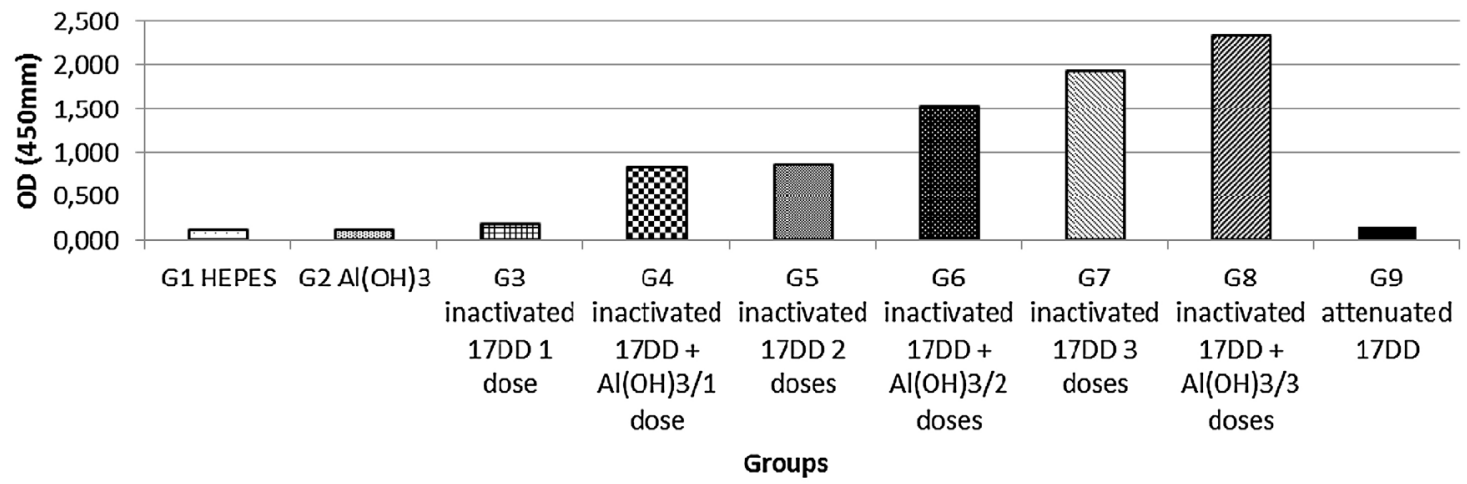

B

IgG2a

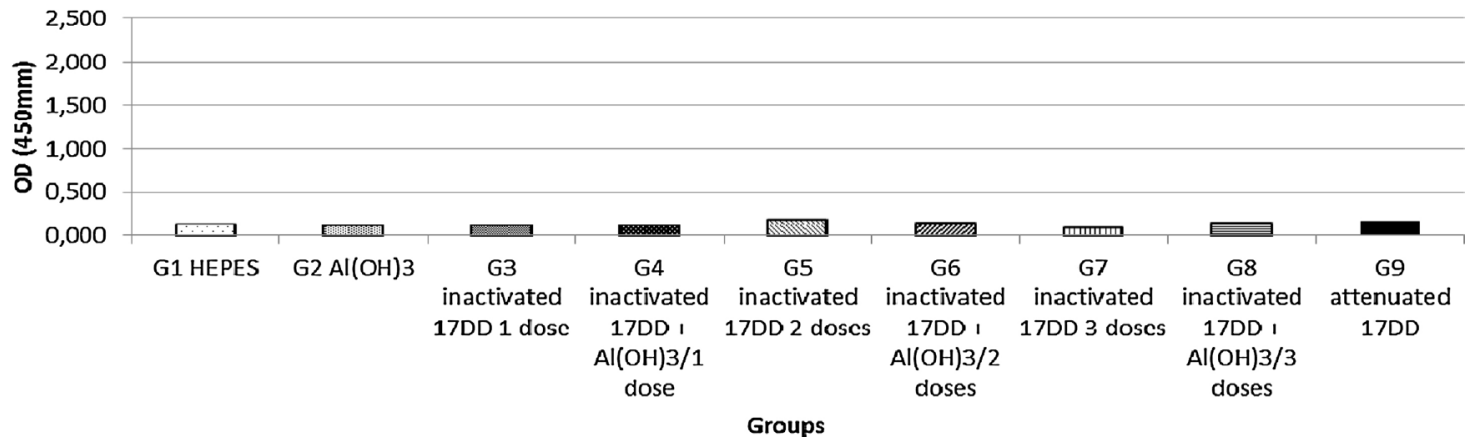

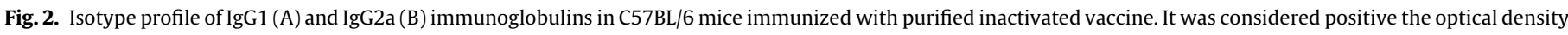
$(450 \mathrm{~nm})>0.3$. 
retained after inactivation process in order to obtain a high-quality antigen. For this, it is essential to have an efficient quality control in the development of inactivated vaccines [16,17].

Problems such as the presence of residual live virus or loss of immunogenicity after viral inactivation by phenol and formaldehyde have been reported during attempts to develop an inactivated vaccine for yellow fever using inactivation by heat and ultraviolet radiation $[18,19]$. The presence of infectious virus in poliovirus vaccine that was inactivated by formalin generated 250 cases of paralysis after mass vaccination in California in 1955. Sixteen batches were retested and live virus was found in the first six batches demonstrating the importance of an efficient process control in the production of inactivated vaccines [20,21].

Bio-Manguinhos is developing an inactivated vaccine for yellow fever from the 17DD, a highly attenuated virus, which is a relevant point considering an improved safety profile for an inactivated vaccine. Nevertheless, in this work, a rigorous control of live infectious particles through different methods was made after viral inactivation processes ensuring the absence of residual live virus.

Inactivation procedures can affect the viral protein by denaturing ( $\mathrm{pH}$ or temperature) or by forming bridges between amino acids constituting the protein (formaldehyde or glutaraldehyde) which may modify the viral epitopes that are essential for the induction of neutralizing antibodies. The use of alkylating agents such as $\beta$ propiolactone (BPL) acting in the viral genome with little or no effect on viral proteins is highly recommended for the generation of an effective vaccine $[17,22]$. The use of BPL in rabies and influenza virus has been widely described and resulted in known commercial vaccines $[23,24]$. The inactivation of the viral genome is also important to ensure the safety of the vaccine through the impossibility of replication. Gaspar et al. described a methodology for inactivation of the 17DD virus vaccine by hydrostatic pressure. The preclinical results in mice showed that the inactivated vaccine was able to induce neutralizing antibody titers and protected animals after challenge with the 17DD virus [25]. However, when it was observed that viral nucleic acid was able to be infectious when transfected to Vero cells, this inactivation platform had to be aborted.

In recent years, some studies have shown that there are still no in vitro tests to replace in vivo immunogenicity and challenge in mice. The strain chosen for the tests was the C57BL/6 which has emerged as an excellent model to study immunogenicity of flaviviruses [26].

In the present study, the immunogenicity assay aimed to determine the minimum number of doses able to enhance the production of neutralizing antibodies and protect C57BL/6 mice after challenge of inactivated vaccine for yellow fever (at a concentration of $2 \mu \mathrm{g} / \mathrm{dose}$ ) in the presence of alum. The $2 \mu \mathrm{g} / \mathrm{dose}$ concentration is within the range used in licensed vaccines for other flaviviruses based on inactivated virus, such as Japanese encephalitis and tickborne encephalitis, using $6 \mu \mathrm{g} /$ dose and $2.4 \mu \mathrm{g} / \mathrm{dose}$, respectively $[27,28]$. At present, inactivated yellow fever vaccine developed by Xcellerex (XRX-001), which is in clinical phase of development, uses the concentration of $4.8 \mu \mathrm{g} /$ dose [29]. The use of low concentration of antigens in a vaccine is always an important step in the establishment of preclinical and clinical studies, because it is associated with technical and economic viability of the commercial product $[8,30]$.

Neutralizing antibody titers of mice sera were determined by $\mathrm{PRNT}_{50}$ and among serological tests available for the evaluation of specific host response is one of the most sensitive and specific [31]. PRNT $_{50}$ is widely accepted and is used for humoral response evaluation of other vaccines that use yellow fever vaccine virus as a vector [32], the XRX-001 inactivated vaccine [8] and in trials that led to the licensure of inactivated vaccine for Japanese encephalitis [33].

The design of the immunogenicity assay allowed to observe the importance of the use of an adjuvant to increase neutralizing antibodies titers by comparing the GMTs of the groups immunized with three doses of inactivated vaccine in the absence of alum adjuvant (group 7: $2 \mu \mathrm{g} /$ dose) with the result in the presence of adjuvant (group 8: $2 \mu \mathrm{g} / \mathrm{dose}+\mathrm{Al}(\mathrm{OH})_{3}$ ). Values of $433 \mathrm{mIU} / \mathrm{mL}$ and $922 \mathrm{mIU} / \mathrm{mL}$ were found, respectively, for these groups, demonstrating that only the group 8 was able to show GMT above the cut-off ( $794 \mathrm{mIU} / \mathrm{mL}$ or $2.9 \log _{10} \mathrm{mIU} / \mathrm{mL}$ ). Groups immunized with two or three doses of vaccine with adjuvant also showed higher survival rates after intracerebral challenge with the 17DD virus than groups immunized with two or three doses of vaccine without adjuvant. The inactivated vaccine containing adjuvant, when administered in three doses (group 8) showed similar protection profile to the attenuated vaccine in a single dose inducing protection of $100 \%$ of the animals after challenge.

The neutralizing antibody is the main correlate of protection against infection with the yellow fever virus [34]. Surprisingly, group 8 showed $43.75 \%$ seroconversion and was still able to induce protection of all animals. This occurrence was also observed by Monath and colleagues who obtained similar results after challenge with 17D virus of hamsters inoculated with low and medium concentration of XRX-001 inactivated yellow fever vaccine, presenting $30 \%$ seroconversion/90\% survival and $80 \%$ seroconversion/100\% survival, respectively [8]. The lack of correlation between neutralizing antibodies rates and protection indicate that the effectiveness of this vaccine might have participation of cellular response and not exclusively humoral response through neutralizing antibodies. It is well known that attenuated yellow fever vaccine is a potent inducer of CD4+ and CD8+ T cells [34]. In fact, it has been previously demonstrated that the attenuated 17DD vaccine is able to induce an early IFN- $\gamma$ response in monkeys as well as in C57BL/6 immunization, which is related to the excellent neutralizing antibodies and CD8+ T cell responses observed for this vaccine [26,35]. In the present work, the presence of IFN- $\gamma$ by ELISPOT was not detected in the splenocytes of animals immunized with the 17DD inactivated vaccine (data not shown) suggesting that further tests have to be performed to better characterize the involved cellular response.

The concentration of $2 \mu \mathrm{g} /$ dose of 17DD inactivated vaccine containing adjuvant (three doses) was able to induced $100 \%$ protection of animals after challenge with the virus 17DD despite the low concentration of viral antigen. An increase in this concentration could decrease the number of doses needed for protection and the use of other adjuvant replacing aluminum hydroxide could drive for greater humoral and cellular responses, enhancing the immune response.

The inactivated vaccine under development intended to replace the attenuated vaccine, at least as a prime boost immunization schedule for avoiding adverse events while inducing durable responses [36]. It is not possible to estimate an annual manufacturing capacity using the current processing conditions.

The reduction of the number of doses is important for emergency vaccination in cases of outbreaks, when immunization by various doses is not possible. However, Schuller and colleagues compared the immunogenicity and protection of vaccine for Japanese encephalitis when administered in two doses of $6 \mu \mathrm{g}$ (0 DPI and $28 \mathrm{DPI}$, which is the standard administration of vaccination for Japanese encephalitis), a single dose of $6 \mu \mathrm{g}$ and a dose of $12 \mu \mathrm{g}$ (which could be used in outbreak situations). The study indicated that the high dose of antigen $(12 \mu \mathrm{g})$ resulted in greater seroconversion than a single lowest dose $(6 \mu \mathrm{g})$. However, after two doses of $6 \mu \mathrm{g}$, seroconversion was higher than the induced by a single dose of the highest concentration. Thus, two doses of $6 \mu \mathrm{g}$ were more immunogenic than a single dose with a high concentration of antigen. Studies have shown that for inactivated vaccines, two doses are preferred to guarantee maximal induction of neutralizing antibodies [27]. 
Scientific literature shows that antigens used in inactivated vaccines are poorly immunogenic and the achievement of a minimal dose that provides commercial value only occurs through the use of adjuvants that can enhance the humoral and cellular response $[8,30]$. Aluminum hydroxide is widely used in licensed vaccines, including vaccines for flaviviruses, such as Japanese encephalitis and tick-borne encephalitis $[27,28]$. This adjuvant may increase the half-life of the antigen, improve absorption by phagocytes, and activate the inflamassoma/NALP3 route, inducing the production of interleukin IL-1 $\beta$ and IL-18 and favoring the differentiation of Th2 cells [37]. It also has the remarkable ability to increase antibody titers after vaccination, but does not induce Th1 response, which is important for intracellular pathogens control [38].

The $17 \mathrm{D}$ virus has the ability to induce IFN- $\gamma$ production, activating the Th1 subset of helper T cells [26,35]. In mice, Th1 immune response is associated with the production of IgG2a, IgG2b and IgG3 antibodies, while Th2 subset is associated with the production of IgG1 [39]. While the binding of the antibody to the virus has the potential to neutralize the infection directly, physiologically these interactions occur in the presence of serum proteins capable of modulating the functions of antibodies. The complement system is a component of the innate immune response able to recognize the pathogen and eliminate it through a complex cascade of cleavage events. The classical complement pathway is activated by the interaction between the $\mathrm{C} 1 \mathrm{q}$ complement protein and the Fc portion of the antibody molecule. The IgG2a antibody, induced by Th1 subset binds with greater affinity to the C1q protein than IgG1 antibody produced by Th2 subset. Thus, in the Th1 subset occurs greater participation of complement, which has been shown to increase the neutralizing activity against many viruses, including flaviviruses [40].

Effect of alum adjuvant in direct response to Th2 with production of IgG1 could be evidenced in groups 6 and 8, which after immunization with inactivated vaccine containing adjuvant showed high concentrations of IgG1 antibodies. This subclass of immunoglobulin was able to protect $100 \%$ of mice after three doses of inactivated vaccine containing $\mathrm{Al}(\mathrm{OH})_{3}$ (group 8). The absence of immunoglobulin IgG1 and IgG2a in the group 9 (commercial attenuated vaccine) can be explained by the collection time (40 DPI), where the response can still be IgM or may be formed by other subclasses of immunoglobulins. However, it may be further investigated.

\section{Conclusions}

In this study, immunization of C57BL/6 mice with three doses ( $2 \mu \mathrm{g} /$ dose $)$ of inactivated vaccine containing alum adjuvant was able to elicit high neutralizing antibodies titers, mostly of the IgG1 isotype, giving $100 \%$ of protection after the lethal challenge. New studies are being conducted using other adjuvants, aiming to maintain protection with dose sparing and dose ranging.

\section{Conflict of interest statement}

\section{No conflicts of interest are declared.}

\section{Acknowledgements}

We thank the Instituto de Tecnologia em Imunobiológicos/BioManguinhos/FIOCRUZ for continued interest and support to this work. We also thank Fernanda Rimolli de Castro Araujo and Sheila Maria Barbosa de Lima for the use of animal and virological facilities, respectively. This work was supported in part by the Programa de Desenvolvimento Tecnológico em Insumos para Saúde Pública
(PDTSP) from FIOCRUZ and Financiadora de Estudos e Projetos (FINEP).

\section{References}

[1] Kummerer BM. The molecular biology of yellow fever virus. In: Kalitzky M, Borowski P, editors. Molecular biology of the flavivirus. Norfolk, UK: Cromwell Press; 2006. p. 1-16.

[2] Gardner CL, Ryman KD. Yellow fever: a reemerging threat. Clin Lab Med 2010;30:237-60

[3] Monath TP. Yellow fever: an update. Lancet Infect Dis 2001;1:11-20.

[4] Vasconcelos PF. Febre amarela [Yellow fever]. Rev Soc Bras Med Trop 2003;36(2):275-93.

[5] Monath TP. Yellow fever vaccine. Expert Rev Vaccines 2005;4:553-74

[6] Pugachev KV, Guirakhoo F, Trent DW, Monath TP. Traditional and novel approaches to flavivirus vaccines. Int J Parasitol 2003;33:567-82.

[7] Franco O. Ministério da Saúde. Departamento Nacional de Endemias Rurais. História da febre amarela no Brasil [Ministry of Health. National Department of Rural Endemic Diseases. History of yellow fever in Brazil]. Rio de Janeiro, RJ: Ministério da Saúde[[nl]]Ministry of Health; 1976

[8] Monath TP, Lee CK, Julander JG, Brown A, Beasley DW, Watts DM, et al. Inactivated yellow fever 17D vaccine: development and nonclinical safety, immunogenicity and protective activity. Vaccine 2010;14(28):3827-40.

[9] Barrett AD, Teuwen DE. Yellow fever vaccine-how does it work and why do rare cases of serious adverse events take place? Curr Opin Immunol 2009;21:308-13.

[10] Vasconcelos PF, Luna EJ, Galler R, Silva LJ, Coimbra TL, Barros VL, et al. Serious adverse events associated with yellow fever 17DD vaccine in Brazil: a report of two cases. Lancet 2001;358:91-7.

[11] Monath TP. Review of the risks and benefits of yellow fever vaccination including some new analyses. Expert Rev Vaccines 2012;11:427-48.

[12] Pato TP, Souza MC, Silva NA, Pereira RC, Silva MV, Caride E, et al. Development of a membrane adsorber based capture step for the purification of yellow fever virus. Vaccine 2014;24:2798-893.

[13] Simões M, Camacho LAB, Yamamura AMY, Miranda EH, Cajaraville ACRA, Freire MS. Evaluation of accuracy and reliability of the plaque reduction neutralization test (micro-PRNT) in detection of yellow fever virus antibodies. Biologicals 2012;40:399-404

[14] Tomori O. Yellow fever: the recurring plague. Crit Rev Clin Lab Sci 2004:41:391-427.

[15] Pugachev KV, Guirakhoo F, Monath TP. New developments in flavivirus vaccines with special attention to yellow fever. Curr Opin Infect Dis 2005;18:387-94.

[16] Josefsberg JO, Buckland B. Vaccine process technology. Biotechnol Bioeng 2012:109:1443-60.

[17] Delrue I, Verzele D, Madder A, Nauwynck HJ. Inactivated virus vaccines from chemistry to prophylaxis: merits, risks and challenges. Expert Rev Vaccines 2012:11:695-719.

[18] Hindle E. A yellow fever vaccine. Br Med J 1928;1(3518):976-7.

[19] Gordon JE, Hughes TP. A study of inactivated yellow fever virus as immunizing agent. J Immunol 1936;30:221-34.

[20] Nathanson N, Langmuir AD. The Cutter incident. Poliomyelitis following formaldehyde-inactivated poliovirus vaccination in the United States during the Spring of 1955. II. Relationship of poliomyelitis to cutter vaccine. Am J Hyg 1963:78:29-60.

[21] Juskewitch JE, Tapia CJ, Windebank AJ. Lessons from the Salk polio vaccine: methods for and risks of rapid translation. Clin Transl Sci 2010;3:182-5.

[22] Uittenbogaard JP, Zomer B, Hoogerhout P, Metz B. Reactions of $\beta$-propiolactone with nucleobase analogues, nucleosides, and peptides: implications for the inactivation of viruses. J Biol Chem 2011;286:36198-214.

[23] Perez O, Paolazzi CC. Production methods for rabies vaccine. J Ind Microbiol 1997:18:340-7.

[24] Stauffer F, El-Bacha T, Da Poian AT. Advances in the development of inactivated virus vaccines. Recent Pat Antiinfect Drug Discov 2006;1:291-6.

[25] Gaspar LP, Mendes YS, Yamamura AM, Almeida LF, Caride E, Gonçalves RB, et al. Pressure-inactivated yellow fever 17DD virus: implications for vaccine development. J Virol Methods 2008;150:57-62.

[26] Neves PC1, Santos JR, Tubarão LN, Bonaldo MC, Galler R. Early IFN-gamma production after YF 17D vaccine virus immunization in mice and its association with adaptive immune responses. PLoS ONE 2013;8:e81953.

[27] Schuller E, Klade CS, Wolfl G, Kaltenbock A, Dewasthaly S, Tauber E. Comparison of a single, high-dose vaccination regimen to the standard regimen for the investigational Japanese encephalitis vaccine, IC51: a randomized, observerblind, controlled Phase 3 study. Vaccine 2009;27:2188-93.

[28] Zent O, Hennig R, Banzhoff A, Broker M. Protection against tick-borne encephalitis with a new vaccine formulation free of protein-derived stabilizers. J Travel Med 2005;12:85-93.

[29] Monath TP, Fowler E, Johnson CT, Balser J, Morin MJ, Sisti M, et al. An inactivated cell-culture vaccine against yellow fever. N Engl J Med 2011;364 1326-33.

[30] Durbin AP, Whitehead SS. Dengue vaccine candidates in development. Curr Top Microbiol Immunol 2010;338:129-43.

[31] Monath TP. Yellow fever vaccine. In: Plotkin S, Orenstein WA, editors. Vaccines. 4th ed. Philadelphia, PA: Elsevier; 2004. p. 1095-176.

[32] Guirakhoo F, Kitchener S, Morrison D, Forrat R, McCarthy K, Nichols R, et al. Live attenuated chimeric yellow fever dengue type 2 (ChimeriVax-DEN2) vaccine: 
phase I clinical trial for safety and immunogenicity: effect of yellow fever preimmunity in induction of cross neutralizing antibody responses to all 4 dengue serotypes. Hum Vaccines 2006;2:60-7.

[33] Hombach J, Solomon T, Kurane I, Jacobson J, Wood D. Report on a WHO consultation on immunological endpoints for evaluation of new Japanese encephalitis vaccines, WHO, Geneva, 2-3 September, 2004. Vaccine 2005;23:5205-11.

[34] Pulendran B. Learning immunology from the yellow fever vaccine: innate immunity to systems vaccinology. Nat Rev Immunol 2009;9:741-7.

[35] Neves PC, Rudersdorf RA, Galler R, Bonaldo MC, de Santana MG, Mudd PA, et al. CD8+ gamma-delta TCR+ and CD4+ T cells produce IFN-gamma at 5-7 days after yellow fever vaccination in Indian rhesus macaques, before the induction of classical antigen-specific T cell responses. Vaccine 2010;28:8183-8, 29.
[36] Monath TP, Vasconcelos PFC. Yellow fever. J Clin Virol 2015;64:160-73.

[37] Eisenbarth SC, Colegio OR, O'Connor W, Sutterwala FS, Flavell RA. Crucial role for the Nalp3 inflammasome in the immunostimulatory properties of aluminium adjuvants. Nature 2008;453:1122-6.

[38] Hoft DF, Brusic V, Sakala IG. Optimizing vaccine development. Cell Microbio 2011;13:934-42.

[39] Germann T, Bongartz M, Dlugonska H, Hess H, Schmitt E, Kolbe L, et al. Interleukin-12 profoundly up-regulates the synthesis of antigen-specific complement-fixing IgG2a, IgG2b and IgG3 antibody subclasses in vivo. Eur J Immunol 1995;25:823-9.

[40] Dowd KA, Pierson TC. Antibody-mediated neutralization of flaviviruses: a reductionist view. Virology 2011;41:306-15. 